\title{
What Role Does Trabecular Bone Score Play in Chronic Inflammatory Rheumatic Diseases?
}

\author{
Barbara Ruaro ${ }^{1 * t}$, Andrea Casabella ${ }^{2,3 t}$, Luigi Molfetta ${ }^{4}$, Francesco Salton ${ }^{1}$, \\ Paola Confalonieri ${ }^{1}$, Marco Confalonieri ${ }^{1}$, Elisa Baratella ${ }^{5}$, Antonio De Tanti ${ }^{6}$ and \\ Cosimo Bruni ${ }^{7}$
}

${ }^{1}$ SC Pneumologia, ASUGI, Trieste, Italy, ${ }^{2}$ Research Laboratory and Academic Division of Clinical Rheumatology, Department of Internal Medicine, San Martino Polyclinic Hospital, University of Genoa, Genoa, Italy, ${ }^{3}$ Department of Internal Medicine Di.M.I, Osteoporosis, Bone and Joint Disease Research Center, CROPO, University of Genoa, Genoa, Italy, ${ }^{4}$ Department of Integrated Surgical and Diagnostic Sciences, School of Medical and Pharmaceutical Sciences, University of Genoa, Genoa, Italy, ${ }^{5}$ Department of Radiology, Department of Medicine, Surgery and Health Science, University of Trieste, Trieste, Italy, ${ }^{6}$ Cardinal Ferrari Centre, S. Stefano Rheabilitation, Fontanellato, Italy, ${ }^{7}$ Division of Rheumatology, Department of Experimental and Clinical Medicine, University of Firenze, Florence, Italy

OPEN ACCESS

Edited by:

Lai-Shan Tam,

The Chinese University of

Hong Kong, China

Reviewed by:

Bruno Vidal.

University of Lisbon, Portugal

João Eurico Fonseca,

University of Lisbon, Portugal

*Correspondence:

Barbara Ruaro

barbara.ruaro@yahoo.it

tThese authors have contributed equally to this work and share first authorship

Specialty section:

This article was submitted to Rheumatology,

a section of the journal

Frontiers in Medicine

Received: 30 August 2020 Accepted: 12 November 2020 Published: 30 November 2020

Citation:

Ruaro B, Casabella A, Molfetta L, Salton F, Confalonieri $P$, Confalonieri M, Baratella E, De Tanti A and Bruni C (2020) What Role Does

Trabecular Bone Score Play in Chronic Inflammatory Rheumatic Diseases?

Front. Med. 7:600697.

doi: 10.3389/fmed.2020.600697
Patients suffering from rheumatic inflammatory diseases, e.g., systemic sclerosis, rheumatoid arthritis, and ankylosing spondylitis, are at risk of low bone mass. Dual-energy $X$-ray Absorptiometry (DXA) is the traditional radiological measurement technique for bone mineral density (BMD). The recently developed trabecular bone score (TBS) enhances the skeletal information provided by standard BMD. It re-analyzes the spatial dynamics of pixel intensity changes in lumbar spine DXA images, defining a quantitative index, characterizing trabecular bone microarchitecture. It has been demonstrated that low TBS values are associated with an increased incidence of fractures in patients with rheumatic diseases. These methods used together for bone damage evaluation can be of value to identify individuals who will potentially fracture. The main scientific literature on the clinical aspects of osteoporosis, including the use of TBS in evaluating this pathology, are herein reported aimed at shedding light on the role trabecular bone score plays in chronic inflammatory rheumatic diseases.

Keywords: osteoporosis, rheumatic diseases, Trabecular Bone Score (TBS), Bone Mineral Density (BMD), osteopaenia

\section{HIGHLIGHTS}

- Patients affected by rheumatic diseases are prone to an increased risk of low bone mass.

- The trabecular bone score provides information on the bone microstructure of patients with rheumatic diseases.

- Patients with rheumatic diseases have lower TBS values than healthy subjects.

\section{INTRODUCTION}

The trabecular bone score (TBS) a grayscale measurement of texture which is derived from the evaluation of the experimental variogram obtained from the Dual-energy X-ray Absorptiometry (DXA) images, is a relatively new tool to evaluate bone microarchitecture (1). TBS is an indirect measurement of bone axial microarchitecture, providing information on bone quality, 
e.g., trabecular quantity, trabecular separation, connectivity density, and Parfitt parameters (1-3). Previous reports proposed a normal TBS value for post-menopausal women of 1.350 or more; conversely, scores between 1.200 and 1.350 were attributed to a partially degraded microarchitecture and a TBS below 1.200 , a degraded microarchitecture (3-5). These cut-off points were established by analogy with the three bone mineral density (BMD) categories, i.e., normal bone mass, osteopenia and osteoporosis (OP) (3-5). More recently, Anderson et al. developed reference ranges for TBS suitable for use in a clinical setting in an Australian male cohort: scores equal to, or lower than, 1.003 were considered for the determination of degraded microarchitecture (6). The authors also demonstrated a linear life-time decrease in TBS amongst the males, (whereas the decrease in women is better modeled with a cubic function) (6). The strength of TBS lies in its ability to provide more information on the potential risk of vertebral fractures than the DXA and $\mathrm{BMD}$. Indeed, its use as an adjuvant to the standard DXA exam was approved by both the Food and Drug Administration (FDA) and the European Medicines Agency (EMA) $(4,7,8)$. Despite this, to date, there are no guidelines on how to apply it to standard practice, even if the World Health Organization (WHO) established operational definitions of osteoporosis (OP) and osteopenia in postmenopausal Caucasian women $(4,5,7$, 8). These were based on BMD values and aimed at guiding researchers and clinicians in the classification of degrees of bone loss, as early as 1994. Several studies reported that patients with chronic rheumatic inflammatory diseases have a higher $\mathrm{OP}$ and osteopenia risk, based on $\operatorname{BMD}(5,7,8)$. However, several limitations in BMD sensitivity have been reported, such as its low power in determining bone quality $(5,7,8)$, an important factor when assessing bone fragility. Indeed, it has recently been demonstrated that bone microarchitecture plays a pivotal role in bone strength. Evidence to date indicates that the TBS bone texture index is able to add further skeletal information to that obtained by the standard BMD $(6,9-11)$. Several studies confirmed that TBS can discriminate patients with altered bone microstructure and have proposed its use as a clinical-radiological tool in OP diagnosis in patients with chronic inflammatory rheumatic diseases, such as systemic sclerosis (SSc), systemic lupus erythematosus (SLE), rheumatoid arthritis (RA), and ankylosing spondylitis (AS) (12-18).

\section{TBS AND SYSTEMIC SCLEROSIS}

SSc is a connective tissue disease characterized by early microvascular impairment, skin, and internal organ fibrosis (19-26). Several studies have also recently demonstrated an increased risk of OP in SSc patients, correlated with multiple factors, i.e., low vitamin $\mathrm{D}$ levels $(1,5,13,15,27)$. Other studies have reported lower BMD and TBS values in SSc patients compared to healthy matched controls $(1,2,5,13)$. Ruaro et al. reported that SSc patients with a "Late" nailfold capillaroscopy pattern had lower TBS values than patients with an "Active" or "Early" pattern ("Late" vs. "Active" and "Early" pattern, $p<0.001)(5,13)$; whilst no statistically significant difference in $\mathrm{BMD}$ values was observed when comparing the three different capillaroscopy patterns $(5,13)$. The negative correlation between the reduced bone microarchitecture, evaluated by TBS, and the progression of microvascular damage studied by nailfold videocapillaroscopy (NVC), suggested that the microvascular damage in SSc patients is also correlated to bone impairment and other systemic complications $(5,13,22,26)$. Furthermore, these studies confirmed that SSc patients have a higher OP and osteopenia risk associated with the BMD obtained by DXA $(1,2,5,13,15)$. Various articles report that TBS is an index of bone texture which is able to enhance the skeletal information obtained by the standard BMD, also in SSc patients $(2,5,13)$. Indeed, several reports demonstrated that bone microarchitecture plays a pivotal role in bone strength and that TBS can be a clinical tool for OP diagnosis in scleroderma patients $(1,2,5,13)$.

Bone damage may have multi-factorial underlying causes: disability, age, longstanding diseases, low Body Mass Index (BMI), chronic systemic inflammation, low vitamin D levels, and some treatment regimes $(1,2,5,13,27)$. Numerous authors demonstrated the presence of lower serum 25-hydroxy-vitamin D $(25(\mathrm{OH}) \mathrm{D})$ levels in SSc patients than in healthy subjects (HS) $(5,13,27)$. Two recent studies have reported that the $25(\mathrm{OH}) \mathrm{D}$ level is significantly lower in the "Late" than in the "Active" or "Early" capillaroscopy pattern patients $(p=0.002)$, probably attributable to a reduced vitamin $\mathrm{D}$ intestinal absorption $(5,13$, 27). The same studies demonstrated that a positive $25(\mathrm{OH}) \mathrm{D}$ value correlated with TBS but not with BMD, as also observed by Koumakis et al. (2). Ruaro et al. reported that there were statistically significant lower bone alkaline phosphatase (bone ALP) levels in SSc patients than in HS and that the "Late" pattern patients had lower ALP levels than those with an "Active" or "Early" one, probably due to a reduced turnover and neobone formation $(5,13,27)$. Furthermore, there was a positive correlation between the TBS and the bone ALP values $(p<$ 0.0001 ) and a negative correlation with the onset of Raynaud's phenomenon in the SSc patients $(p<0.01)$. Conversely, there was no statistically significant correlation between the TBS values and calcium or phosphorus blood levels $(5,13)$.

In conclusion, all these studies demonstrated that SSc patients run a high risk of having low bone mass and support the importance of evaluating the different aspects of bone architecture with DXA, TBS, and bone parameters, such as vitamin D circulating levels, as part of the periodical clinical assessment $(1,2,5,13,27)$.

\section{TBS AND SYSTEMIC LUPUS ERYTHEMATOSUS}

Systemic lupus erythematosus (SLE) is a complex systemic autoimmune disease, characterized by a wide spectrum of clinical and serological manifestations (14, 28-30). Recent studies have demonstrated a higher incidence of $\mathrm{OP}$ and bone fractures in SLE patients compared to HS (14, 30-36). The bone loss observed in SLE has a multi-factorial etiology, including: systemic inflammation, kidney impairment, nutritional disorders, serological, metabolic, and hormonal factors and 
maybe also genetic factors and drugs, such as glucocorticoids (GC) (14, 30-40). Moreover, a high prevalence of morphometric vertebral fractures has been observed in SLE patients, despite the fact that $1 / 3$ of them had normal bone density, in line with the hypothesized multi-factorial etiology of fractures in SLE $(14,30-40)$. Indeed, long-term use of corticosteroids may induce OP in SLE patients by influencing bone turnover (increasing bone resorption and decreasing bone formation), preventing the formation of collagen and osteocalcin, as well as reducing the bone matrix mineralization $(14,30-40)$. Moreover, numerous cytokines are involved in OP pathogenesis, due to their influence on osteoblast and osteoclast function, i.e., IL-33 (35, 37-39). Vitamin D deficiency may also be a predisposing factor for bone loss in SLE $(14,35,37-39)$. Several studies have demonstrated that SLE patients have an increased risk of low bone mass, assessed by DXA and TBS $(14,30-40)$.

Lai et al. and Ruaro et al. emphasized the important role TBS plays as an innovative and safe diagnostic tool for the quantification of bone quality in chronic and systemic inflammatory rheumatic diseases, such as those observed in SLE. In fact, both studies confirmed that SLE patients have a higher risk of bone loss (osteopenia and $\mathrm{OP}$ ) and fractures than do HS $(34,40)$.

Lai et al. analyzed 147 SLE patients and observed that TBS had a higher diagnostic accuracy for vertebral fractures than densitometric measurements (area in the ROC curve for TBS, L spine and left femur BMD: 0.811 vs. 0.737 and 0.605 , respectively), supporting the assessment of bone microarchitecture by TBS as an enhancer of the information provided by BMD and showing that TBS identified degraded microarchitecture mainly associated with vertebral fractures in SLE patients (34).

Ruaro et al. were the first to evaluate bone involvement in SLE and compare the results with matched HS, using TBS and DXA (40). They observed that the lumbar spine TBS score was significantly lower in SLE patients than in HS $(p<0.001)$ and that BMD was significantly lower in all areas (the lumbar spine, femoral neck, Ward's triangle, trochanter, and hip) than in HS $(p<0.001$, for all areas) (40). Furthermore, this study showed that SLE patients had an increased prevalence of $25(\mathrm{OH})$ vitamin D insufficiency $(p<0.001)$ than HS, as frequently reported in rheumatic diseases $(36,40)$. Interestingly, SLE patients with previous fractures had statistically significantly lower vitamin $D$ values than those without $(p<0.0001)(36,40)$.

Another recent study has indicated that supplementation with high vitamin D doses (1.400 IU cholecalciferol per day) and calcium carbonate $(1.250 \mathrm{mg}$ per day) for 6 months improved bone mineral density and decreased the osteopenia and OP rates in corticosteroid-treated patients. Most likely, vitamin D can activate osteoblast and bone formation, as well as decrease bone resorption, through the inactivation of osteoclasts (37-39).

Therefore, we consider the early identification of OP and osteopenia is a must in a SLE subjects with "fragile bones," as is the set-up of specific diagnostic-therapeutical strategies. Enhanced knowledge of bone pathophysiology, coupled to progress in pharmaceutical development, has provided the opportunity to make early identification of subjects at high risk of fragility fractures and to start preventive therapy for fractures.

\section{TBS AND RHEUMATOID ARTHRITIS}

Rheumatoid arthritis (RA) is a chronic inflammatory disease which affects the joints, with progressive and destructive consequences and may also have extra-articular manifestations $(41,42)$.

These manifestations could be related to the localization of the rheumatoid process in other tissues, i.e., serosa (pericardium, pleura), skin (rheumatoid nodules) or medical therapy complications, such as OP $(41,42)$.

Some studies reported that the frequency of OP in women with RA ranged from 30 to 50\%, depending on the areas assessed by the DXA, this datum was also confirmed in males (43); osteopenia had a prevalence of about $80 \%$ (43). Several factors may lead to adverse effects on bone mass and to an increased risk of fracture in RA patients, i.e., reduced sun exposure leading to low serum $25(\mathrm{OH})$ vitamin D levels, reduced physical activity, proximal muscle atrophy due to a sedentary lifestyle, prolonged use of GC and disease-induced bone mass reduction. Indeed, RA patients tend to develop early OP and are prone to fragility fractures $(2,9,12,43-45)$.

Several studies have demonstrated decreased BMD values using DXA but only a few studies have made use of TBS in RA patients. Breban et al. proposed evaluating the diagnostic TBS as a complement to the BMD on DXA or as an independent risk factor for vertebral fractures (VF) in populations on GC or anti-TNF therapy (43). TBS values were lower in patients on GC compared to those who were not $(p=0.0001)$. Furthermore, TBS was significantly lower in VF patients compared to those without fractures $(p=0.0001)$ and it had a better discrimination value to predict VF in RA patients than the lumbar spine BMD alone $(43,45)$.

TBS was assessed in patients with RA and AS and compared with healthy subjects (HS) in a case-control study by Toussirot et al. (44). Moreover, they made a prospective examination of the changes in the BMD values of lumbar spine and hip, along with the TBS values whilst on anti-TNF drugs. The study enrolled 30 RA and 30 AS patients not on GC and a comparative HS group of 50 subjects. TBS values from L2 to L4 were measured and the BMD and T-Score were evaluated at the hip in RA patients. They observed that both values were significantly lower in the RA subjects than in the HS $(p=0.005)$. Interestingly, the subgroup of 20 patients on anti-TNF (8 RA and 12 AS patients) monitored for 2 years during the perspective phase of the study, showed a significant increase in the lumbar spine BMD values $(+6.3$ and $+2.4 \%$, respectively, for RA and AS). However, TBS significantly decreased in RA patients, whilst it remained stable in AS patients, which may be explained by the different influences these drugs have on the bone. The final analysis of the study showed that TBS in RA patients on anti-TNF allows for a greater discrimination of the population at lumbar spine fracture risk, increasing the percentage of the population to be treated with anti-osteoporotic therapies compared to the data provided by DXA alone (44). 
Koumakis et al. and Ruaro et al. compared RA, SSc, and HS using TBS and DXA in conjunction $(2,5)$. Koumakis et al. observed no significant difference in the average lumbar spine TBS values between RA and SSc patients; similarly, BMD at the lumbar spine, femoral neck, and total hip did not differ among the three groups. The fracture prevalence was similar in the RA and SSc groups ( 29.2 vs. $33.3 \%$, respectively, $p=0.682$ ). The TBS values did not differ between RA and HS $(p=0.128)$, despite lower cumulative and daily GC dose $(p<0.0001)$. Furthermore, no association between GC and TBS was observed in the RA group (2). Ruaro et al. selected 98 RA patients on a daily GC dose of $<5 \mathrm{mg} /$ day and $60 \mathrm{HS}$. They observed that 78/98 of the RA group (80\%) had bone loss at DXA and BMD. BMD was significantly lower in RA patients than in the control group $(p<0.001)$ (5). Similarly, lumbar spine TBS was significantly lower in RA patients than in HS $(p<0.001)$. Furthermore, their study confirmed that $25(\mathrm{OH})-\mathrm{D}$ serum levels were statistically significantly lower in RA patients than in HS ( $p<0.001)(5)$.

Similar results were confirmed by Casabella et al., who evaluated 108 females affected by RA and 60 HS. They performed DXA and TBS at the level of the lumbar spine (L1-L4) and evaluated the serum $25(\mathrm{OH})$ vitamin $\mathrm{D}$ concentrations, for all patients. The lumbar spine TBS score was significantly lower in RA sufferers compared to HS ( $p<0.001)$. Moreover, subjects with RA had lower $25(\mathrm{OH})$ vitamin D concentrations than HS $(p<0.04)(45)$.

\section{TBS AND ANKYLOSING SPONDYLITIS}

AS is a chronic inflammatory form of arthritis involving the axial skeleton $(46,47)$, affecting the spinal vertebrae and sacroiliac joints, causing debilitating pain and loss of mobility. It has been proposed that the sites of attachment of the ligaments or tendons to the bone, known as entheses, are the major target of the inflammatory, traumatic, and degenerative pathological changes occurring in AS (46-48). Enthesitis is believed to play a primary role in the ligament calcification process, which leads to pain. It can cause reduced flexibility of the spine and eventually complete loss of spinal mobility, destruction as well as ankylosis (fusion) of the spine and sacroiliac joints.

New bone formation, which includes the development of syndesmophytes and ankylosis of the spine, is almost pathognomonic for AS (47-51).

The altered new bone formation in the vertebral cortical area and the impairment of trabecular bone at the level of the vertebral body increase the risk of both OP and VF. Furthermore, these bone alterations and ligament ossification modify the BMD data and falsely increase lumbar spine BMD values $(41,47,51)$.

Since AS mainly affects young men and BMD gives falsely increased values, there is often a delay in prevention and/or treatment of $\mathrm{OP}$ in this condition. Therefore, appropriate bone assessment to determine bone strength, microstructure and any ossifications is a must to start correct treatment in routine practice $(17,18,47-51)$.

Toussirot et al. assessed TBS in 30 patients with RA and AS compared the data to those of $50 \mathrm{HS}$, also including 20 patients who had been on anti-TNF drugs for 2 years (44). The lumbar spine BMD did not differ between AS and HS patients, whilst there was a decrease in the hip T-score in AS patients $(p=$ 0.02 ) (44). Several studies reported a $25 \%$ OP prevalence in AS patients and from 10 to $43 \%$ radiographic vertebral fractures (17, 18, 47-51).

Ivanova et al. evaluated the relationship between physical function, disease activity, spine mobility, and bone parameters, TBS and BMD, in AS patients (50). The study concluded that lumbar BMD can be affected by osteoproliferation and that, despite this, AS patients have a lower TBS score than HS. Moreover, more evident alterations are also reported in bone microarchitecture in older patients, without significant differences between genders. There was an inverse correlation between the mobility scores and the three bone parameters (TBS, $\mathrm{BMD}$, and T-score femoral), showing a relationship between the state of skeletal health and vertebral functional deterioration (50).

Recently, Richards et al. reported the first analysis of TBS for fracture prediction as an incident event in AS: TBS was shown to independently predict major osteoporotic and clinical spine fractures in AS, whatever the FRAX score (48). Similar predictive power was confirmed by Nam et al., who studied 215 AS patients (75.8\% males) and reported that TBS could predict the risk of major osteoporotic fractures. They also stated that TBS is not influenced by spinal osteo-proliferation in AS patients, even in those with advanced spinal changes $(49,51)$.

These data could overcome the bias derived from previous reports with falsely elevated DXA values at the level of the lumbar spine in AS (49-51). This finding is most likely due to the fact that DXA measures only the quantity and not the quality of the bone, therefore confirming its limitations for fracture prediction in this patient group.

\section{TBS AND OTHER RHEUMATIC DISEASES}

Recent studies reported that TBS could also be useful in other rheumatic diseases, such as osteoarthritis (OA) and polymyalgia rheumatica (PMR) (52-54). Kolta et al. enrolled 1,254 menopausal women and evaluated 727 of them for 6-years. Patients with lumbar OA had a higher BMD than those without lumbar OA at the lumbar spine, but not at the hip. Conversely, spine TBS did not differ between patients with or without lumbar OA $(p=0.70)$. Interestingly, there was a negative correlation between spine TBS and BMD at all sites and age $(p<0.0001)(52)$. In conclusion, numerous studies have shown that whilst BMD values can be overestimated in patients with OA, TBS evaluations do not seem to be affected by OA changes in the lumbar spine. Furthermore, as TBS is mildly impacted by OA, it could be a better predictor of fracture than spine $\operatorname{BMD}(52,53)$.

Several studies reported that TBS could also be a supplementary tool to discriminate osteoporotic fractures in postmenopausal patients with PMR (54). Kim et al. compared BMD, TBS and the frequency of VF in patients with PMR, RA, or HS. The researchers demonstrated that in PMR patients had a significantly higher VF frequency than RA and HS patients ( $p=$ $0.017)$. The average TBS in PMR patients was significantly lower 
TABLE 1 | Milestones in the study of bone microarchitecture analyzed by trabecular bone score (TBS) in rheumatic diseases.

\begin{tabular}{|c|c|c|c|c|}
\hline Authors & $\begin{array}{l}\text { Study } \\
\text { type }\end{array}$ & $\begin{array}{l}\text { Rheumatologic } \\
\text { population }\end{array}$ & $\begin{array}{l}\text { Control } \\
\text { population }\end{array}$ & $\begin{array}{l}\text { Summary of } \\
\text { results }\end{array}$ \\
\hline Kounakis et al. (2) & CS & 138 RA, W & $227 \mathrm{mHC}$ & $\begin{array}{l}\text { TBS did not differ between controls and RA patients, despite lower cumulative, } \\
\text { and daily glucocorticoid (GC) dose. No association between GC and TBS was } \\
\text { found in RA }\end{array}$ \\
\hline Choi et al. (9) & CS & $279 \mathrm{RA}, \mathrm{pW}$ & NA & $\begin{array}{l}\text { The TBS was negatively correlated with the cumulative dose of glucocorticoids } \\
\text { (GCs), but not with the disease activity score for } 28 \text { joints (DAS28) or erythrocyte } \\
\text { sedimentation rate }\end{array}$ \\
\hline Casabella et al. (12) & $P$ & $55 \mathrm{RA}, \mathrm{W}$ & $55 \mathrm{mHC}$ & $\begin{array}{l}\text { Most of RA patients ( } 80 \%) \text { had lower BMD than control group Lumbar spine TBS } \\
\text { was found significantly lower in RA patients compared with } \mathrm{mHC} \text { Positive } \\
\text { correlation between the TBS and relative skeletal mass index (RSMI) in } \\
\text { RA patients }\end{array}$ \\
\hline Ruaro et al. (13) & $P$ & $60 \mathrm{RA}, \mathrm{W}$ & $60 \mathrm{mHC}$ & $\begin{array}{l}\text { The BMD values and the T-score measured on the vertebral column, the femoral } \\
\text { neck, and the whole femur were significantly lower in RA patients than those in } \\
\text { the control group Lumbar spine TBS was found significantly lower in RA patients } \\
\text { compared with } \mathrm{mHC}\end{array}$ \\
\hline Kim et al. (16) & $\mathrm{P}$ & $100 \mathrm{RA}, \mathrm{W}$ aged $\geq 50$ & NA & $\begin{array}{l}\text { Twenty-six patients were revealed to have moderate to severe vertebral fractures } \\
\text { There was a modest negative correlation between fracture risk assessment score } \\
\text { (FRAX) and TBS. There was no correlation between FRAX and L-spine BMD }\end{array}$ \\
\hline Breban et al. (43) & $\mathrm{P}$ & 185 RA, W & NA & $\begin{array}{l}\text { T-scores were significantly lower in patients with VFs than in patients without } \\
\text { VFs, the largest difference being observed at femoral neck. TBS was significantly } \\
\text { lower in patients with VFs vs. without VFs }\end{array}$ \\
\hline Toussirot et al. (44) & $\mathrm{CC}, \mathrm{P}$ & $30 \mathrm{RA}, \mathrm{W}$ & $50 \mathrm{mHC}$ & $\begin{array}{l}\text { RA patients had lower BMD, lower T score, and lower TBS at the hip compared } \\
\text { to } \mathrm{mHC} \text { Under anti-TNFa, in patients with RA, TBS score decreased }\end{array}$ \\
\hline Casabella et al. (45) & $\mathrm{P}$ & $108 \mathrm{RA}, \mathrm{W}$ & $60 \mathrm{mHC}$ & $\begin{array}{l}78 \text { RA patients }(80 \%) \text { presented a bone loss that was significantly lower when } \\
\text { compared with } \mathrm{mHC} \text {. Lumbar spine TBS score was significantly lower in RA } \\
\text { patients compared with } \mathrm{mHC}\end{array}$ \\
\hline Ruaro et al. (5) & $\mathrm{P}$ & 84 SSc, pW & $60 \mathrm{mHC}$ & $\begin{array}{l}\text { TBS and BMD were significantly lower in SSc patients than in mHC TBS values } \\
\text { were found to be lower in SSc with a "Late" nailfold videocapillaroscopy (NVC) } \\
\text { pattern, compared with the "Active" or "Early" patterns }\end{array}$ \\
\hline Ruaro et al. (13) & $\mathrm{P}$ & 60 SSc pW & $60 \mathrm{mHC}$ & $\begin{array}{l}\text { The SSc patients showed higher Dkk-1 serum levels than mHC SSc patients, } \\
\text { showing the "Late" NVC pattern had statistically higher Dkk-1 serum levels than } \\
\text { patients with either the "Active" or "Early" patterns Only in the "Late" NVC } \\
\text { pattern group of SSc patients was there a significant negative correlation } \\
\text { between Dkk-1 and TBS values }\end{array}$ \\
\hline Ruaro et al. (40) & $\mathrm{P}$ & 40 SLE, W & $40 \mathrm{mHC}$ & $\begin{array}{l}\text { The lumbar spine TBS score was statistically significantly lower in SLE patients } \\
\text { than in } \mathrm{mHC}\end{array}$ \\
\hline Casabella et al. (14) & $P$ & 70 SLE, W & $65 \mathrm{mHC}$ & $\begin{array}{l}\text { Lumbar spine TBS score and BMD value were found significantly lower in SLE } \\
\text { patients compared with CNT }\end{array}$ \\
\hline Caparbo et al. (18) & $\mathrm{P}$ & 73 AS, M & $52 \mathrm{mHC}$ & $\begin{array}{l}\text { No difference was observed in lumbar spine BMD in AS patients and CNT, but } \\
\text { total hip BMD and TBS were lower in AS patients }\end{array}$ \\
\hline Nam et al. (49) & $\mathrm{P}$ & 215 AS, $75.8 \% M$ & NA & $\begin{array}{l}\text { TBS, hip BMD, and L-spine lateral BMD showed comparably high areas under } \\
\text { the curve for predicting FRAX-major osteoporotic fractures. TBS negatively } \\
\text { correlated with modified Stoke AS Spine Score (mSASSS) in both male and } \\
\text { female patients }\end{array}$ \\
\hline Toussirot et al. (44) & $\mathrm{P}$ & $30 \mathrm{AS}, 27 \mathrm{M}$ & $50 \mathrm{mHC}$ & $\begin{array}{l}\text { Hip T score in patients with AS was also decreased Lumbar spine (LS) BMD did } \\
\text { not differ between patients and } \mathrm{mHC} \text {, whileTBS was lower in AS compared to } \\
\text { HC LS and hip BMD increased after } 24 \text { months under anti-TNFa, with significant } \\
\text { changes at the spine in patients with AS, TBS progressively increased }\end{array}$ \\
\hline Ivanova et al. (50) & $\mathrm{P}$ & $50 \mathrm{AS}, 27 \mathrm{M}, 23 \mathrm{~W}$ & NA & $\begin{array}{l}\text { Lumbar spine BMD can be erroneously influenced by osteoproliferation, unlike } \\
\text { the TBS and TBS T-score. The limitations in spinal mobility predicted abnormal } \\
\text { results for these two TBS parameters }\end{array}$ \\
\hline Wildberger et al. (51) & $\mathrm{P}$ & $51 \mathrm{AS}, \mathrm{M}$ & NA & $\begin{array}{l}\text { axSpA men with and without syndesmophytes have lower results compared to } \\
\text { the normal population regarding hip BMD, spine TBS, and spine BMD except for } \\
\text { men with syndesmophytes who have a normal BMD spine T-score }\end{array}$ \\
\hline
\end{tabular}


TABLE 1 | Continued

\begin{tabular}{|c|c|c|c|c|}
\hline Authors & $\begin{array}{l}\text { Study } \\
\text { type }\end{array}$ & $\begin{array}{l}\text { Rheumatologic } \\
\text { population }\end{array}$ & $\begin{array}{l}\text { Control } \\
\text { population }\end{array}$ & $\begin{array}{l}\text { Summary of } \\
\text { results }\end{array}$ \\
\hline Boussonalim et al. (17) & $\mathrm{P}$ & 95 axSpA & NA & $\begin{array}{l}\text { Lumbar BMD was positively correlated with TBS, while disease duration, disease } \\
\text { activity score and serum PTH levels were negatively correlated with TBS More } \\
\text { than half of the patients with a BMD level above }-2.5 \text { T-score had a low } \\
\text { TBS value }\end{array}$ \\
\hline Kolta et al. (52) & $\mathrm{P}$ & $\begin{array}{l}1,254 \text { patients (including } \\
\text { patients with } \mathrm{OA} \text { ), pW }\end{array}$ & & $\begin{array}{l}\text { Patients with lumbar osteoarthritis had an BMD higher than those without lumbar } \\
\text { osteoarthritis at the lumbar spine, but not at the hip. In contrast, spine TBS was } \\
\text { not different between patients with and without lumbar osteoarthritis }\end{array}$ \\
\hline Kim et al. (54) & CS, P & 53 PMR pW & $106 \mathrm{mHC}$ & $\begin{array}{l}\text { The mean TBS of patients with PMR was significantly lower than those in CNT } \\
\text { TBS could be a supplementary tool for discriminating osteoporotic fractures in } \\
\text { postmenopausal patients with PMR }\end{array}$ \\
\hline
\end{tabular}

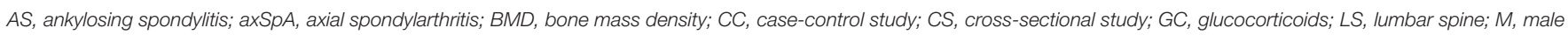

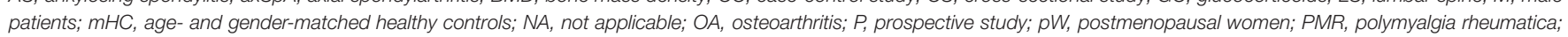
RA, rheumatoid arthritis; SLE, systemic lupus erythematosus; SSc, systemic sclerosis; TBS, trabecular bone score; VF, vertebral fractures; W, women.

than that of RA and HS patients $(p<0.001)$. Their multivariate analysis demonstrated that a lower TBS is associated with VF in PMR patients $(p=0.043)$. In conclusion, TBS is a promising technique, even if further studies should be carried out to clarify the role this technique plays in other specific rheumatic disorders (see Table 1).

\section{CONCLUSIONS}

Various imaging techniques able to provide direct information on trabecular bone microarchitecture are currently available, such as magnetic resonance and computed tomography. However, their use in clinical practice is hampered by the fact that they are expensive, not always readily available and can examine only the peripheral bone area (18).

There is increasing evidence that TBS values are associated with the incidence of fractures in rheumatic diseases. TBS provides data on trabecular bone microarchitecture, as it is an index of bone texture and enhances the information obtained by the standard BMD. DXA and TBS, used together for bone damage evaluation, can be of value to identify individuals with potentially increased risk on bone fractures and, therefore, guide treatment decisions, particularly in patients with complicated diseases such as rheumatic inflammatory disorders $(1,5,13,50$, $54,55)$.

\section{REFERENCES}

1. Avouac J, Koumakis E, Toth E, Meunier M, Maury E, Kahan A, et al. Increased risk of osteoporosis and fracture in women with systemic sclerosis: a comparative study with rheumatoid arthritis. Arthritis Care Res. (2012) 64:1871-8. doi: 10.1002/acr.21761

2. Koumakis E, Avouac J, Winzenrieth R, Toth E, Payet J, Kahan A, et al. Trabecular bone score in female patients with systemic sclerosis: comparison with rheumatoid arthritis and influence of glucocorticoid exposure. J Rheumatol. (2015) 42:228-35. doi: 10.3899/jrheum.140752

3. Parfitt AM, Mathews CH, Villanueva AR, Kleerekoper M, Frame B, Rao DS. Relationships between surface, volume, and thickness of iliac trabecular bone in aging and in osteoporosis. Implications for the microanatomic
In conclusion, current evidence supports the use of an integrated assessment plan with TBS and BMD in conjunction, offering advantages in clinical practice over the use of BMD alone when facing the assessment of bone status, also in rheumatic diseases $(1,5,50,54-57)$. Moreover, future research agenda should aim at further studies investigating into the role of TBS as an outcome measure in the evaluation of anti-osteoporotic treatment efficacy.

\section{AUTHOR CONTRIBUTIONS}

$\mathrm{BR}, \mathrm{AC}$, and $\mathrm{CB}$ : made substantial contributions to the conception and design of the work, the acquisition, analysis, and interpretation of data, drafting the work and revising it critically for important intellectual content, and the final approval of the version to be published. LM, FS, PC, MC, and $\mathrm{AD}$ : made substantial contributions to the analysis and interpretation of data and final approval of the version to be published. All authors contributed to the article and approved the submitted version.

\section{ACKNOWLEDGMENTS}

The authors would like to thank Barbara Wade, contract Professor at the University of Torino for her linguistic advice.

and cellular mechanisms of bone loss. J Clin Invest. (1983) 72:1396409. doi: 10.1172/JCI111096

4. Harvey NC, Glüer CC, Binkley N, McCloskey EV, Brandi ML, Cooper $\mathrm{C}$, et al. Trabecular bone score (TBS) as a new complementary approach for osteoporosis evaluation in clinical practice. Bone. (2015) 78:21624. doi: 10.1016/j.bone.2015.05.016

5. Ruaro B, Casabella A, Paolino S, Pizzorni C, Alessandri E, Seriolo C, et al. Correlation between bone quality and microvascular damage in systemic sclerosis patients. Rheumatology. (2018) 57:1548-54. doi: 10.1093/ rheumatology/key130

6. Anderson KB, Holloway-Kew KL, Hans D, Kotowicz MA, Hyde NK, Pasco JA. Reference ranges for trabecular bone score in australian men and women: a cross-sectional study. JBMR Plus. (2019) 3:e10133. doi: 10.1002/jbm4.10133 
7. Kanis JA, Cooper C, Rizzoli R, Reginster JY. European guidance for the diagnosis and management of osteoporosis in postmenopausal women. Osteoporos Int. (2019) 30:3-44. doi: 10.1007/s00198-018-4704-5

8. Shevroja E, Lamy O, Kohlmeier L, Koromani F, Rivadeneira F, Hans D. Use of trabecular bone score (TBS) as a complementary approach to dual-energy X-ray absorptiometry (DXA) for fracture risk assessment in clinical practice. $J$ Clin Densitom. (2017) 20:334-45. doi: 10.1016/j.jocd.2017.06.019

9. Choi YJ, Chung YS, Suh CH, Jung JY, Kim HA. Trabecular bone score as a supplementary tool for the discrimination of osteoporotic fractures in postmenopausal women with rheumatoid arthritis. Medicine. (2017) 96:e8661. doi: 10.1097/MD.0000000000008661

10. Schacter GI, Leslie WD, Majumdar SR, Morin SN, Lix LM, Hans D. Clinical performance of an updated trabecular bone score (TBS) algorithm in men and women: the Manitoba BMD cohort. Osteoporos Int. (2017) 28:3199203. doi: 10.1007/s00198-017-4166-1

11. Hans D, Stenova E, Lamy O. The trabecular bone score (TBS) complements DXA and the FRAX as a fracture risk assessment tool in routine clinical practice. Curr Osteoporos Rep. (2017) 15:521-31. doi: 10.1007/s11914-0170410-z

12. Casabella A, Ruaro B, Seriolo C, Molfetta L, Alessandri E, Pizzorni C, et al. Sarcopenia in rheumatoid arthritis female patients: relationship between whole body and trabecular bone score. Ann Rheum Dis. (2019) 78:1367. doi: 10.1136/annrheumdis-2019-eular.5425

13. Ruaro B, Casabella A, Paolino S, Pizzorni C, Ghio M, Seriolo C, et al. Dickkopf-1 (Dkk-1) serum levels in systemic sclerosis and rheumatoid arthritis patients: correlation with the Trabecular Bone Score (TBS). Clin Rheumatol. (2018) 37:3057-62. doi: 10.1007/s10067-018-4322-9

14. Casabella A, Paolino S, Alessandri E, Smith V, Ruaro B, Pizzorni C, et al. Trabecular bone score in systemic lupus erythematosus patients. Ann Rheum Dis. (2020) 79:1198. doi: 10.1136/annrheumdis-2020-eular.4180

15. Omair MA, Pagnoux C, McDonald-Blumer H, Johnson SR. Low bone density in systemic sclerosis. a systematic review. J Rheumatol. (2013) 40:188190. doi: 10.3899/jrheum.130032

16. Kim D, Cho SK, Kim JY, Choi YY, Sung YK. Association between trabecular bone score and risk factors for fractures in Korean female patients with rheumatoid arthritis. Mod Rheumatol. (2016) 26:5405. doi: 10.3109/14397595.2015.1101212

17. Boussoualim K, Amouzougan A, Pallot-Prades B, Denarié D, Collet $\mathrm{P}$, Marotte $\mathrm{H}$, et al. Evaluation of bone quality with trabecular bone score in active spondyloarthritis. Joint Bone Spine. (2018) 85:727-31. doi: 10.1016/j.jbspin.2018.02.006

18. Caparbo VF, Furlam P, Saad CGS, Alvarenga JC, Aubry-Rozier B, Hans $\mathrm{D}$, et al. Assessing bone impairment in ankylosing spondylitis (AS) using the trabecular bone score (TBS) and high-resolution peripheral quantitative computed tomography (HR-pQCT). Bone. (2019) 122:813. doi: 10.1016/j.bone.2019.01.024

19. Ruaro B, Smith V, Sulli A, Pizzorni C, Tardito S, Patané M, et al. Innovations in the assessment of primary and secondary raynaud's phenomenon. Front Pharmacol. (2019) 10:360. doi: 10.3389/fphar.2019.00360

20. Ruaro B, Soldano S, Smith V, Paolino S, Contini P, Montagna P, et al. Correlation between circulating fibrocytes and dermal thickness in limited cutaneous systemic sclerosis patients: a pilot study. Rheumatol Int. (2019) 39:1369-76. doi: 10.1007/s00296-019-04315-7

21. Ruaro B, Pizzorni C, Paolino S, Alessandri E, Sulli A. Aminaphtone efficacy in primary and secondary raynaud's phenomenon: a feasibility study. Front Pharmacol. (2019) 10:293. doi: 10.3389/fphar.2019.00293

22. Ruaro B, Nallino MG, Casabella A, Salton F, Confalonieri P, De Tanti A, et al. Monitoring the microcirculation in the diagnosis and follow-up of systemic sclerosis patients: focus on pulmonary and peripheral vascularmanifestations. Microcirculation. (2020). doi: 10.1111/micc.12647. [Epub ahead of print].

23. Hoffmann-Vold AM, Allanore Y, Bendstrup E, Bruni C, Distler O, Maher TM, et al. The need for a holistic approach for SSc-ILD - achievements and ambiguity in a devastating disease. Respir Res. (2020) 21:197. doi: 10.1186/ s12931-020-01459-0

24. Bruni C, Cuomo G, Rossi FW, Praino E, Bellando-Randone S. Kidney involvement in systemic sclerosis: from pathogenesis to treatment. JSRD. (2018) 3:43-52. doi: 10.1177/2397198318758607
25. Bruni C, De Luca G, Lazzaroni MG, Zanatta E, Lepri G, Airò P, et al. Screening for pulmonary arterial hypertension in systemic sclerosis: a systematic literature review. Eur J Intern Med. (2020) 78:17-25. doi: 10.1016/j.ejim.2020.05.042

26. Smith V, Scirè CA, Talarico R, Airo P, Alexander T, Allanore Y, et al. Systemic sclerosis: state of the art on clinical practice guidelines. RMD Open. (2018) 4(Suppl. 1):e000782. doi: 10.1136/rmdopen-2018-000788

27. Trombetta AC, Smith V, Gotelli E, Ghio M, Paolino S, Pizzorni C, et al. Vitamin D deficiency and clinical correlations in systemic sclerosis patients: a retrospective analysis for possible future developments. PLoS ONE. (2017) 12:e0179062. doi: 10.1371/journal.pone.0179062

28. Mirabelli G, Cannarile F, Bruni C, Vagelli R, De Luca R, Carli L. One year in review 2015: systemic lupus erythematosus. Clin Exp Rheumatol. (2015) 33:414-25.

29. Tamirou F, Arnaud L, Talarico R, Scirè CA, Alexander T, Amoura Z, et al. Systemic lupus erythematosus: state of the art on clinical practice guidelines. RMD Open. (2018) 4:e000793. doi: 10.1136/rmdopen-2018-000793

30. Salman-Monte TC, Torrente-Segarra V, Vega-Vidal AL, Corzo P, CastroDominguez F, Ojeda F, et al. Bone mineral density and vitamin D status in systemic lupus erythematosus (SLE): a systematic review. Autoimmun Rev. (2017) 16:1155-9. doi: 10.1016/j.autrev.2017.09.011

31. Wada Y, Hasegawa H, Saeki T, Ito S, Kuroda T, Nakano M, et al. Longterm prognosis and factors associated with damage accrual in Japanese patients with systemic lupus erythematosus. Clin Exp Nephrol. (2018) 22:597602. doi: 10.1007/s10157-017-1491-9

32. Bultink IEM. Bone disease in connective tissue disease/systemic lupus erythematosus. Calcif Tissue Int. (2018) 102:575-91. doi: 10.1007/s00223-0170322-z

33. Mendoza-Pinto C, Rojas-Villarraga A, Molano-González N, JiménezHerrera EA, León-Vázquez ML, Montiel-Jarquín Á, et al. Bone mineral density and vertebral fractures in patients with systemic lupus erythematosus: a systematic review and meta-regression. PLOS ONE. (2018) 13:e0196113. doi: 10.1371/journal.pone.0196113

34. Lai EL, Huang WN, Chen HH, Chen JP, Chen DY, Hsieh TY, et al. Degraded microarchitecture by low trabecular bone score is associated with prevalent vertebral fractures in patients with systemic lupus erythematosus. Arch Osteoporos. (2020) 15:54. doi: 10.1007/s11657-020-00726-3

35. Adami G, Fassio A, Rossini M, Caimmi C, Giollo A, Orsolini G, et al. Osteoporosis in rheumatic diseases. Int J Mol Sci. (2019) 20:5867. doi: 10.3390/ijms20235867

36. Casabella A, Paolino S, Alessandri E, Smith V, Ruaro B, Pizzorni C, et al. Evaluation of bone quality by trabecular bone score (TBS) in systemic lupus erythematosus patients. Ann Rheum Dis. (2019) 78:945-6. doi: 10.1136/ annrheumdis-2019-eular.6753

37. Al-Kushi AG, Azzeh FS, Header EA, ElSawy NA, Hijazi HH, Jazar AS, et al. Effect of vitamin D and calcium supplementation in patients with systemic lupus erythematosus. Saudi J Med Med Sci. (2018) 6:13742. doi: 10.4103/sjmms.sjmms_134_17

38. Singh A, Kamen DL. Potential benefits of vitamin D for patients with systemic lupus erythematosus. Dermatoendocrinol. (2012) 4:14651. doi: 10.4161/derm.20443

39. Paschalis EP, Gamsjaeger S, Hassler N, Fahrleitner-Pammer A, Dobnig H, Stepan JJ, et al. Vitamin D and calcium supplementation for three years in postmenopausal osteoporosis significantly alters bone mineral and organic matrix quality. Bone. (2017) 95:41-6. doi: 10.1016/j.bone.2016.11.002

40. Ruaro B, Casabella A, Paolino S, Alessandri E, Patané M, Gotelli E, et al. Trabecular bone score and bone quality in systemic lupus erythematosus patients. Front Med. (2020) 7:574842. doi: 10.3389/fmed.2020.574842

41. Bugatti S, Bozzalla Cassione E, De Stefano L, Manzo A. Established rheumatoid arthritis. the pathogenic aspects. Best Pract Res Clin Rheumatol. (2019) 33:101478. doi: 10.1016/j.berh.2019.101478

42. Gavrilă BI, Ciofu C, Stoica V. Biomarkers in rheumatoid arthritis, what is new? J Med Life. (2016) 9:144-8.

43. Bréban S, Briot K, Kolta S, Paternotte S, Ghazi M, Fechtenbaum J, et al. Identification of rheumatoid arthritis patients with vertebral fractures using bone mineral density and trabecular bone score. J Clin Densitom. (2012) 15:260-6. doi: 10.1016/j.jocd.2012.01.007 
44. Toussirot E, Mourot L, Wendling D, Dumoulin G. Trabecular bone score in rheumatoid arthritis and ankylosing spondylitis and changes during long term treatment with TNF a blocking agents. J Bone Miner Res. (2012) 27:381.

45. Casabella A, Sulli A, Seriolo C, Botticella G, Molfetta L, Cutolo M, et al. Evaluation of bone quality using the new trabecular bone score (TBS) tool in rheumatoid arthritis patients. Ann Rheum Dis. (2017) 76:695. doi: 10.1136/ annrheumdis-2017-eular.6126

46. Smith JA. Update on ankylosing spondylitis: current concepts in pathogenesis. Curr Allergy Asthma Rep. (2015) 15:489. doi: 10.1007/ s11882-014-0489-6

47. Van der Heijde, Maksymowych W. Spondyloarthritis: state of the art and future perspectives. Ann Rheum Dis. (2010) 69:949-54. doi: 10.1136/ard.2009. 119529

48. Richards C, Hans D, Leslie WD. Trabecular Bone Score (TBS) predicts fracture in ankylosing spondylitis: the manitoba BMD registry. J Clin Densitom. (2020) 23:543-8. doi: 10.1016/j.jocd.2020.01.003

49. Nam SW, Sung YK, Kim D, Cho SK, Song Y, Choi YY, et al. The usefulness of trabecular bone score in patients with ankylosing spondylitis. Korean J Intern Med. (2020). doi: 10.3904/kjim.2020.065

50. Ivanova M, Manolova I, Boyadzhieva V, Stoilov R, Dimitrov N, Stoilov N, et al. Relationship between physical function, disease activity, spinal mobility and bone parameters (trabecular bone score and bone mineral density) in ankylosing spondylitis patients. Biotechnol Biotechnol Equipment. (2015) 29:956-62. doi: 10.1080/13102818.2015.1057525

51. Wildberger L, Boyadzhieva V, Hans D, Stoilov N, Rashkov R, Aubry-Rozier B. Impact of lumbar syndesmophyte on bone health as assessed by bone density (BMD) and bone texture (TBS) in men with axial spondyloarthritis. Joint Bone Spine. (2017) 84:463-6. doi: 10.1016/j.jbspin.2016.05.015

52. Kolta S, Briot K, Fechtenbaum J, Paternotte S, Armbrecht G, Felsenberg D, et al. TBS result is not affected by lumbar spine osteoarthritis. Osteoporos Int. (2014) 25:1759-64. doi: 10.1007/s00198-014-2685-6
53. Nassar K, Paternotte S, Kolta S, Fechtenbaum J, Roux C, Briot K. Added value of trabecular bone score over bone mineral density for identification of vertebral fractures in patients with areal bone mineral density in the nonosteoporotic range. Osteoporos Int. (2014) 25:243-9. doi: 10.1007/s00198-0132502-7

54. Kim HA, Lee HY, Jung JY, Suh CH, Chung YS, Choi YJ. Trabecular bone score is a useful parameter for the prediction of vertebral fractures in patients with polymyalgia rheumatica. J Clin Densitom. (2020) 23:373-80. doi: 10.1016/ j.jocd.2019.05.006

55. Weinstein RS. Is long-term glucocorticoid therapy associated with a high prevalence of asymptomatic vertebral fractures? Nat Clin Pract Endocrinol Metab. (2007) 3:86-7. doi: 10.1038/ncpendmet0372

56. Angeli A, Guglielmi G, Dovio A, Capelli G, de Feo D, Giannini S, et al. High prevalence of asymptomatic vertebral fractures in post-menopausal women receiving chronic glucocorticoid therapy: a cross-sectional outpatient study. Bone. (2006) 39:253-9. doi: 10.1016/j.bone.2006.02.005

57. Lewiecki EM. Review of guidelines for bone mineral density testing and treatment of osteoporosis. Curr Osteoporos Rep. (2005) 3:75-83. doi: 10.1007/ s11914-005-0014-x

Conflict of Interest: The authors declare that the research was conducted in the absence of any commercial or financial relationships that could be construed as a potential conflict of interest.

Copyright (C) 2020 Ruaro, Casabella, Molfetta, Salton, Confalonieri, Confalonieri, Baratella, De Tanti and Bruni. This is an open-access article distributed under the terms of the Creative Commons Attribution License (CC BY). The use, distribution or reproduction in other forums is permitted, provided the original author(s) and the copyright owner(s) are credited and that the original publication in this journal is cited, in accordance with accepted academic practice. No use, distribution or reproduction is permitted which does not comply with these terms. 